\title{
Variables Affecting the Gingival Embrasure Space in Aesthetically Important Regions: Differences between Central and Lateral Papillae
}

\author{
Marco Montevecchi ${ }^{1}$, Vittorio Checchi ${ }^{2}$, Laura Piana ${ }^{1}$ and Luigi Checchi ${ }^{1}{ }_{*}$ \\ ${ }^{I}$ Department of Periodontology and Implantology, School of Dentistry, Alma Mater Studiorum - University of Bologna, \\ Bologna, Italy \\ ${ }^{2}$ Department of Odontostomatological, Orthodontic and Surgical Sciences, Second University of Naples, Naples, Italy
}

\begin{abstract}
This study evaluated different variables to determine their role in the appearance of the central and lateral upper jaw papillae. 292 interdental embrasures were examined. Personal variables were: age, smoke, and use of interproximal hygiene devices. The clinical characteristics were: tooth shape, periodontal biotype and papilla appearance. Radiographic measurements were: root to root distance at the cemento-enamel junction (horizontal distance), and bone crest to interdental contact point distance (vertical distance). The papilla recession increased with patient age. The horizontal distance of the central papilla was always greater (up to $1 \mathrm{~mm}$ ) than that of the other papillae. The vertical distance of the central papilla was greater (up to $2 \mathrm{~mm}$ ) than that of the other papillae for each class except for the normal one (Nordland \& Tarnow classification). For vertical distances $\leq 5 \mathrm{~mm}$, papillae were almost always present; for distances up to $6 \mathrm{~mm}$, the lateral papillae belonging to the normal class disappeared, while the central papilla remained in $11 \%$ of cases; central papillae of class 1 were present in larger proportions until a vertical distance of $8 \mathrm{~mm}$. The present observational study shows that differences on clinical and radiographic determinants do exist between central and lateral papillae. This variance should be strictly taken in account for a harmonious and stable treatment outcome on this highly aesthetic area.
\end{abstract}

Keywords: Interdental papilla, soft tissue, aesthetic, measurements, radiography.

\section{INTRODUCTION}

At the base of any harmonious smile there is the equilibrium between symmetry and dimension of the various constituent tissues, of which the periodontal tissues make an important contribution towards both chromatic and morphological imbalances.

One element that contributes to such morphological imbalances is the reduction of the gingival component (commonly referred to as interdental papilla) that lies between two teeth and their point of contact $[1,2]$.

The preservation of this structure is important to avoid the unpleasant presence of the "black triangle". This clinical condition is of major concern for both patients and dentists because the open space below the contact area can lead not only to aesthetic impairment but also to phonic problems and food impaction [3-6].

The loss of interdental papilla can derive from pathological origins, such as periodontal disease, but also from iatrogenic procedures occurring during surgical interventions, from bad habits and inadequate oral hygiene [2].

The loss of the interdental papilla resulting only from soft tissue damage can be completely restored by reconstructive

\footnotetext{
*Address correspondence to this author at the Department of Periodontology and Implantology, School of Dentistry, Alma Mater Studiorum, University of Bologna. Via S. Vitale 59, 40125 Bologna, Italy;

Tel: +39/0512080115; Fax: +39/0514391718;

E-mail: luigi.checchi@unibo.it
}

techniques, but reconstruction is just partial if the loss is due to severe periodontal disease and interproximal bone resorption [6].

A number of studies have been performed in order to discover the factors that lead to the formation or incomplete formation of the papilla between natural teeth $[2-5,7,8]$. Many factors have been correlated to the interdental papilla appearance, such as periodontal biotype or tooth morphology, but interest has mainly been focused upon the dimensions that define the interdental area: the distance between the contact point (CP) and the bone crest (BC), as interradicular distances at different levels.

In the frequently quoted study of Tarnow et al. published in 1992 [5], papillae were found to be present $98 \%$ of the time when the $\mathrm{BC}-\mathrm{CP}$ distance was $5 \mathrm{~mm}$; when the distance was $6 \mathrm{~mm}$, papillae were present $56 \%$ of the time, and when the distance was $7 \mathrm{~mm}$ or more, papillae were present no more than $27 \%$ of the time.

Regarding interradicular distances, a study by Cho $\mathrm{et}$ al. [7] reported that interdental papillae were present in $77.8 \%$ of cases when the interproximal distance at the level of bone crest was $1 \mathrm{~mm}$, in $72.4 \%$ of cases when the distance was 1.5 $\mathrm{mm}$, in $53.7 \%$ of cases when the distance was $2.0 \mathrm{~mm}$, in $35 \%$ of cases when the distance was $2.5 \mathrm{~mm}$, in $23.5 \%$ of cases when the distance was $3.0 \mathrm{~mm}$, and in $6.3 \%$ of cases when the distance was $3.5 \mathrm{~mm}$; it was finally found that the papilla was always lost when the interproximal distance of roots was $\geq 4 \mathrm{~mm}$. 


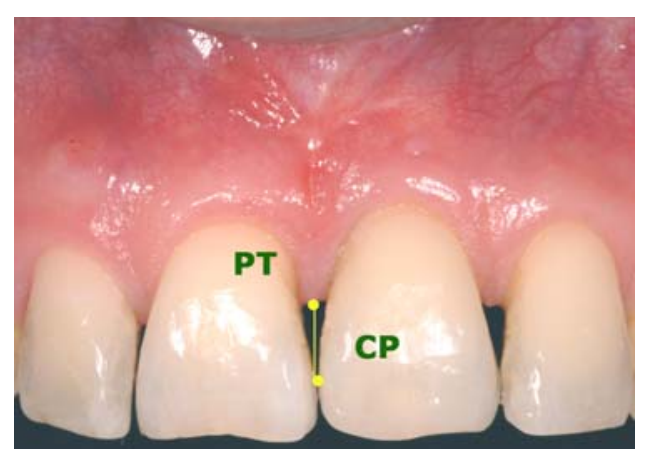

Fig. (1). Clinical appearance of a papilla deficiency between maxillary central incisors. The distance between the Papilla Tip (PT) and the Contact Point $(\mathrm{CP})$ is the papilla recession.

To date, all the studies performed on this subject have analyzed either the upper central papilla alone or have made no distinctions between the interproximal areas studied.

The anatomical differences that exist between the distinct areas could play an important role in determining the shape and response of the interdental papilla. This consideration advocates the need for a specific analysis of the different interproximal areas.

The main purpose of this work was to assess the influences of the previously studied factors upon the aesthetically most important papillae: the lateral and central papillae of the upper jaw. Differences in recession and morphometric distances between these papillae were also investigated because of their important role when a clinician has to decide how to treat dental tissues in aesthetic areas.

\section{MATERIALS AND METHODS}

During 2010, one hundred and three (103) consecutive patients attending for first visit or recall control the Periodontal and Implant Department of the Bologna University were included in this study.

This study was in accordance with the Helsinki Declaration of 1975 , as revised in 2000 , and before entering the study, all subjects were informed about the nature of the study and they all signed an informed consent form.

A total of 292 interdental embrasures within the upper anterior sextant were examined. More specifically, the interdental papillae studied were those between \#12-11, \#11-21 and \#21-22.

Inclusion criteria were healthy gingiva of the upper anterior sextant with a plaque and gingival index of 0-1 [9], "well-on" anterior maxillary incisors (i.e. no spacing, no crowding and no intrusion/extrusion) and recent full mouth radiographic examination (performed no more than 15 days before). Exclusion criteria were: systemic conditions, included pregnancy and medication history known to increase the risk of gingival hyperplasia or alter haemostasis; the presence of artificial crowns, implants, proximal/cervical restorations or abrasions on the anterior maxillary incisors; and previous oral surgery within the anterior maxillary area.

At the initial visit a series of personal, clinical and radiographic variables were collected and investigated. The personal variables were: sex, age and smoking habits. Ten ciga- rettes a day were considered the threshold to distinguish between high smokers and light smokers [10].

All patients were questioned about the hygiene devices they use within the anterior-superior sextant as part of their daily oral hygiene routine.

From a clinical point of view, shape of the teeth, biotypes of the teeth and degree of recession of the papillae under examination were assessed. All clinical measurements were obtained with a standardized periodontal probe* and rounded up to the nearest millimetre. No visual magnification was used. A single operator, blind to the radiographic observations, carried out these measurements.

In order to characterise the shape of the teeth, the height of the crown $(\mathrm{CL})$ and its width $(\mathrm{CW})$ were calculated, measured at the level of the point of passage between cervical third and medial third of the tooth crown. If the CW/CL relationship resulted as being equal to 1, the shape was considered square; if it was less than 1, the shape was considered triangular [11].

The periodontal biotype was determined with the "TRAN technique": the gingival biotype was considered thin when the outline of the periodontal probe showed through the gingival margin from inside the sulcus. Instead if the outline of the underlying periodontal probe could not be visualized through the gingival margin, it was categorized as a thick biotype [12, 13].

The degree of papilla recession (PT-CP) was calculated by measuring the distance between the papilla tip (PT) and the contact point (CP) between the two adjacent teeth (Fig. (1)).

The interdental papillae were subdivided according to the classification system of Nordland \& Tarnow [14].

The radiographic exam used for this study consisted on three periapical radiographs for each patient ${ }^{*}$, taken using the standardized paralleling technique. The three radiographic films included respectively the following teeth: \#1211, \#11-21 and \#21-22.

The intraoral X-ray system used had the following characteristics: $20-25 \mathrm{~mm}$ focal length, $0.4 \mathrm{~mm}$ focal spot, $65 \mathrm{kV}$ and $7 \mathrm{~mA} \mathrm{X}$-ray tube ${ }^{\dagger}$. Exposure times were between 0.160 0.200 seconds. Film holders were used ${ }^{\S}$. The radiographs were developed using an automatic system with fixed temperatures and development times ${ }^{\mathrm{II}}$.

To ensure accurate and correct radiographic measurements, a self adhesive strip containing a radio-dense grid with millimetre squares (XRG, Ada Products, Milwaukee, WI, USA) was applied on the film so that it was imaged on the radiograph but did not overlie the tooth itself. Following the film alignment to the tube, the grid eliminates measurements distortion providing a check of radiographic enlargement [15].

\footnotetext{
*UNC-15, Hu-Friedy, Chicago, IL

** 24x40 mm, Kodak ultra speed DF55

${ }^{\dagger}$ KaVo Dental Corporation - Gendex Dental Systems, USA

${ }^{\S}$ Rinn corporation, USA

"Dür Dental, Germany
} 
Using a 2x magnification lens and millimetre grid square, the radiograph images were studied and the following two measurements taken: 1) the interproximal horizontal distance (HD) at the level of the cementoenamel junction (CEJ) between teeth 12-11, 11-21 and 21-22, and 2) the vertical distance (BC-CP) between the interproximal bone crest (BC) and the contact point (CP) of the same regions (Fig. 2). A single operator, blind to the clinical observations, carried out these measurements.

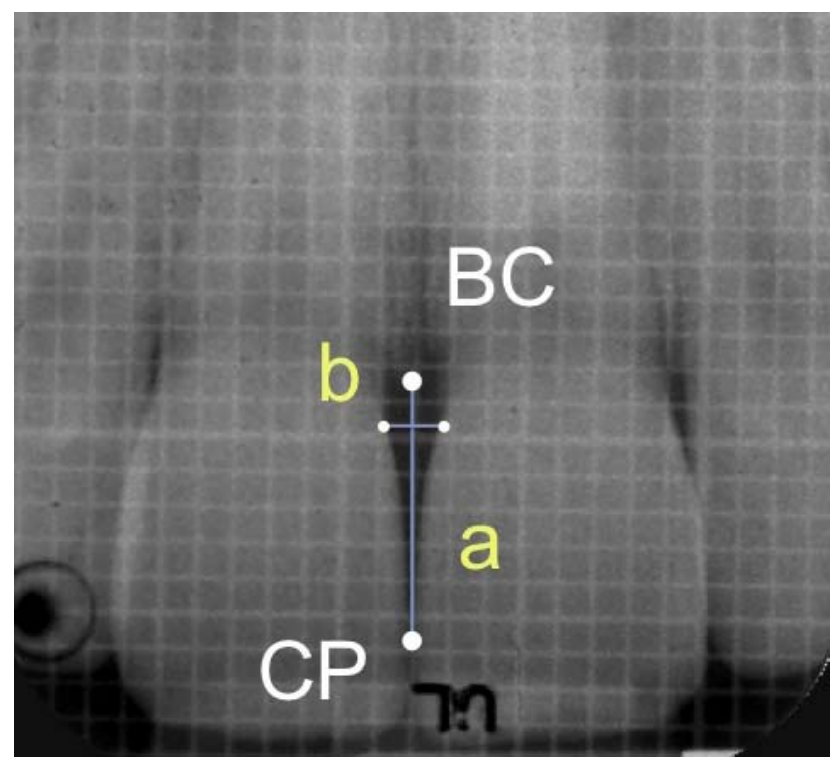

Fig. (2). Periapical radiograph of maxillary central incisors and specific measurements: a) vertical distance $=$ distance from the Bone Crest $(\mathrm{BC})$ to the Contact Point $(\mathrm{CP})$; b) horizontal distance $=$ distance between the two roots at the proximal cementoenamel junction.

The sample size was mainly determined focusing upon the dimensions that define the interdental area: 1) the interproximal horizontal distance at the level of the cementoenamel junction (CEJ) as interradicular distances at different levels between teeth 12-11, 11-21 and 21-22, and 2) the vertical distance (BC-CP) between the interproximal bone crest (BC) and the contact point $(\mathrm{CP})$ of the same regions. The minimal difference in horizontal distance between central and lateral papilla observed as significant was $0.5 \mathrm{~mm}$ on the basis of the difference of interradicular distances shown in a study by Cho et al. [7].

The minimal difference in vertical distance between central and lateral papilla observed as significant was $1 \mathrm{~mm}$ on the basis of the difference of BC-CP distances shown in a study by Tarnow et al. [5].

On the basis of a normal distribution of these variables observed in a pilot sample (lightly positively skewed and leptokurtic), at a significance level $\alpha$ of $0.05\left(z_{\alpha}=1.960\right)$ and with a power of $95 \%\left(z_{\beta}=1.645\right)$, by estimating the standard deviation in a pilot study $(0,770 \mathrm{~mm}$ for the horizontal distance and $1.833 \mathrm{~mm}$ for the vertical distance) the results were: $\mathrm{N}=62$ subjects for the horizontal distance (in total 186 interdental embrasures) and $\mathrm{N}=87$ subjects for the vertical distance (in total 261 interdental embrasures). A final sample of 103 patients was chosen that provided a total number of interdental 292 embrasures.

The statistical unit of the analysis was the papillae. The omnibus test (D'Agostino's $\mathrm{K}^{2}$ test) was used as goodnessof-fit measure of departure from normality, based on transformation of sample kurtosis and skewness. Among the ratio scale variables, only age presented a normal distribution, while all the clinical and radiological variables were significantly $(\mathrm{p}<0.0001)$ non normally distributed. Data are described using mean values (percentages for the nominal and ordinal variables and arithmetic mean and median for the ratio scale variables), variability indicators (standard deviation) and association measures (Spearman's rank correlation coefficient, rho).

Logistic multinomial regression was used to evaluate which of personal (age, smoking habits, hygienic devices), clinical (biotype, shape of teeth, degree of recession) and radiological (interproximal horizontal distance, vertical distance) variables affect the papilla, according to the classification system of Nordland \& Tarnow [14]. Odds ratio and 95\% confidence intervals were used to quantify the influence of each variable and the significance of its contribute; goodness-of-fit test (chi square) and pseudo $\mathrm{R}^{2}$ measure (Nagelkerke statistic) were used to evaluate respectively how well the model fits the observed data and the proportion of variability in the dependent variable that can be explained by the independent variables.

ANOVA was used for the comparison of the age of the patients across the classes of the papillae; Mann-Whitney test was used for comparisons of the degree of recession, the horizontal distance and the vertical distance by biotype, shape of teeth and use of hygienic devices. Kruskal-Wallis analysis of variance was used for comparisons of the degree of recession, the horizontal distance and the vertical distance among the three papillae. All p-values reported were twotailed; a p-value equal to 0.05 was considered as statistically significant and adjusted to 0.008 for multiple comparisons.

\section{RESULTS}

A random sample of about $10 \%$ of the studied patients was chosen for the validation of the intra-examiner repeatability. Therefore each patient of the random sample was reexamined both clinically and radiographically at 1 and 2 weeks after the first recording.

Reliability of clinical and radiographic measurements was obtained by evaluating the intra-operator agreement through Intraclass Correlation Coefficient (Vertical Distance: $\mathrm{ICI}=0.980$, 95\% CI 0.942-0.994 p=0.0001; Papilla Recession: $\mathrm{ICI}=0.926,95 \%$ CI 0.803-0.979, $\mathrm{p}=0.0001$ ).

Reliability of biotype and form was obtained by evaluating the intra-operator agreement through the kappa statistic for nominal data $(\mathrm{K}=0.7, \mathrm{p}<0.01$ for both parameters). Intraobserver agreement may be considered from substantial to almost perfect being above 0.6 [16].

The sample population $(\mathrm{n}=103)$ was formed by $36 \%$ male and $64 \%$ female patients. $83 \%$ of the subjects examined were light/no smokers ( $<10$ cigarettes a day). The mean age 
was $48 \pm 14$ years (range: $18-78$ years). Considering hygiene devices, $58 \%$ of the subjects reported to use interdental brushes (pipe-cleaner heads), $57 \%$ reported the use of dental floss and $42 \%$ the use of stimulator tips.

The "thick" biotype resulted as being more prevalent (53\%) than "thin" (47\%); regarding tooth shapes, square shapes were more frequent (54\%) than triangular (46\%).

The lateral papillae belong predominantly to classes 1 and 2 while the central papilla was primarily identified as class 1 (Table 1); subjects with papillae belonging to the inferior classes were significantly younger than subjects with papillae belonging to the superior classes.

For all the anatomical areas investigated, the horizontal radiographic distance was found to be independent of papilla class, while age, use of interdental brush (except for the central papilla belonging to class 2), radiographic vertical distance (BC-CP) (except for the lateral papilla of the first quadrant belonging to class 2) and degree of papillary recession increased with increasing papilla class (Table 2).

For all the groups of predictors, the goodness-of-fit chisquare was not statistically significant, and Nagelkerke pseudo R-square vary from 0.552 to 0.735 for personal variables, from 0.672 to 0.760 for clinical variables, from 0.631 to 0.717 for radiographic variables to denote that observed data are well represented by the regression models. Also the relationship between age, radiographic vertical distance and level of recession is statistically significant; i.e. both parameters assessed increase with age for each papilla analysed (rho $=0.4$ for the vertical distance and $r h o=0.5$ for the degree of recession; $\mathrm{p} \leq 0.0001$ ).

Concerning clinical and radiographic determinants (Table 3), differences between central and lateral papillae were found. Specifically:

a) the HD for the \#1.1-2.1 papilla was always higher than the ones of \#1.2-1.1 and \#2.1-2.2 in each class ( $p=0.0001$ );

b) the BC-CP for the \#1.1-2.1 papilla was always higher than the ones of \#1.2-1.1 and \#2.1-2.2 in each class, except for the normal class ( $\mathrm{p}=0.011)$;

c) among the three papillary recessions class, one statistically significant difference was observed for the class $1(\mathrm{p}=$ 0.01 ); the recession on the central papilla was greater than on the other two papillae.

The papillary recession is correlated in a statistically significant manner with the vertical distances in all three papillae studied and with the horizontal distances of the central and lateral papillae of quadrant II (Table 4).

Only in relation to the central papilla a statistically significant association emerges between the two radiographic distance measurements taken.

In all the anatomical areas studied it was observed that in subjects with triangular shaped teeth the vertical distances and the degrees of papillary recessions were greater compared to the subjects with square shaped teeth ( $\mathrm{p} \leq 0.03$ ).

From the analyses conducted on the use of interdental hygiene devices, the use of interdental brushes $(\mathrm{p}=0.001)$ is significantly correlated with increases in both the vertical distance (BC-CP) and the degree of papillary recession.

Table 5 and Table $\mathbf{6}$ show the relation between papilla class and horizontal/vertical radiographic distances.

For radiographic vertical distance $\leq 5 \mathrm{~mm}$ only negligible levels of recession were detected in each of the three papillae studied in almost $100 \%$ of cases. With a distance of $6 \mathrm{~mm}$, no lateral papillae were classifiable in normal class, whereas $11 \%$ of central papillae remained present in this class. Moreover, central papillae of class 1 remained present in higher percentages than lateral papillae until a maximum BC-CP distance of $8 \mathrm{~mm}$.

\section{DISCUSSION}

Admitting the high aesthetic value of the interdental papillae and assuming that anatomical differences can exist between the central and the lateral papillae, these evaluations were directed at the three papillae of the upper anterior sextant; specifically, the papillae between the lateral incisors of quadrant I and the lateral incisors of quadrant II were assessed; although, the distinct papillae were considered independently.

In this study, after having investigated which personal (age, smoking, use of hygienic devices), clinical (biotype, shape of teeth, degree of recession) and radiological (horizontal and vertical distances) factors are connected to the papilla appearance, it was observed whether differences actually exist between the analyzed papillae.

Previous studies have either examined only the papilla between the two central incisors $[3,8]$ or different papillae without taking into account the anatomical location [5, 7]. The only study where the upper anterior sextant was specifically studied was performed by Martegani et al. [4], even though the Authors combined data of different papillae into a single set, thus losing the possibility to show anatomical differences between each single papilla.

In order to reduce the number of variables that could influence the papillae appearance and to obtain a sample as homogeneous as possible, patients selected for the present study were limited to the Caucasian race, thus allowing the study to eliminate the eventual race factors and focus upon other variables.

In the study sample, patients exhibiting either a complete presence of papillae or a severe deficit (that would fall into papilla category class 3 ) were poorly represented. The low frequency of complete papillary presence could be consequent to our patient selection criteria (subjects were patients of a University Periodontal Department); the low prevalence of a severe papilla recession within this aesthetic region, suggests instead that such a condition may be unusual.

Studying the correlations between clinical classes [14] and personal variables, it results that age and use of interdental brush affect papilla class.

Analysing the influence of age upon the appearance of the papillae, it emerges that with an age increase the degree 
Table 1. Distribution of the Studied Papillae According to the Nordland \& Tarnow Classification (1998) 14 and Patient Mean Age

\begin{tabular}{|c|c|c|c|c|}
\hline & Class & $\begin{array}{l}\text { Papilla } \\
(\text { n - \%) }\end{array}$ & $\begin{array}{c}\text { Age }(y r) \\
(\text { mean } \pm \text { SD })\end{array}$ & p-Value \\
\hline Papilla \#1.2-1.1 & $\begin{array}{l}\text { Normal } \\
\text { Class } 1 \\
\text { Class } 2 \\
\text { Class } 3\end{array}$ & $\begin{array}{l}23-24.2 \\
24-25.3 \\
28-29.5 \\
19-20.0\end{array}$ & $\begin{array}{l}35.3 \pm 11 \\
43.9 \pm 11 \\
56.6 \pm 11 \\
54.6 \pm 11\end{array}$ & $0.0001^{*}$ \\
\hline Papilla \#1.1-2.1 & $\begin{array}{l}\text { Normal } \\
\text { Class } 1 \\
\text { Class } 2 \\
\text { Class } 3\end{array}$ & $\begin{array}{l}20-20.6 \\
38-39.2 \\
25-25.8 \\
14-14.4\end{array}$ & $\begin{array}{l}34.0 \pm 11 \\
49.1 \pm 13 \\
55.6 \pm 10 \\
55.0 \pm 11\end{array}$ & $0.0001^{*}$ \\
\hline Papilla \#2.1-2.2 & $\begin{array}{l}\text { Normal } \\
\text { Class } 1 \\
\text { Class } 2 \\
\text { Class } 3\end{array}$ & $\begin{array}{l}23-22.8 \\
34-33.7 \\
24-23.8 \\
20-19.8\end{array}$ & $\begin{array}{l}35.4 \pm 13 \\
48.7 \pm 13 \\
53.0 \pm 11 \\
56.0 \pm 10\end{array}$ & $0.0001^{*}$ \\
\hline
\end{tabular}

* Statistically significant

Table 2. Logistic Multinomial Regression Applied to Personal, Clinical and Radiographic Parameters Affecting the Papilla Appearence [Nordland \& Tarnow Classification (1998) $]_{14}$. Only Significant Variables are Reported

\begin{tabular}{|c|c|c|c|c|c|c|c|c|c|c|}
\hline \multirow[t]{3}{*}{ VARIABLE } & \multirow[t]{3}{*}{ CLASSES } & \multicolumn{9}{|c|}{ PAPILLA } \\
\hline & & \multicolumn{3}{|c|}{ \# 1.2-1.1 } & \multicolumn{3}{|c|}{ \# 1.1-2.1 } & \multicolumn{3}{|c|}{ \# 2.1-2.2 } \\
\hline & & O.R. & $p=$ & $95 \% \mathrm{CI}$ & O.R. & $p=$ & $95 \% \mathrm{CI}$ & O.R. & $p=$ & $95 \% \mathrm{CI}$ \\
\hline \multicolumn{11}{|l|}{ Personal } \\
\hline \multirow{3}{*}{ Age } & \multirow{3}{*}{$\begin{array}{l}2 v s \text { normal } \\
3 v s \text { normal } \\
4 v s \text { normal }\end{array}$} & 1.101 & 0.014 & $1.020-1.188$ & 1.110 & 0.004 & $1.033-1.194$ & 1.090 & 0.005 & $1,027-1,158$ \\
\hline & & 1.275 & 0.0001 & $1.139-1.428$ & 1.164 & 0.0001 & $1.071-1.265$ & 1.130 & 0.001 & $1.053-1.213$ \\
\hline & & 1.285 & 0.0001 & $1.135-1.455$ & 1.182 & 0.001 & $1.068-1.308$ & 1.175 & 0.0001 & $1.085-1.271$ \\
\hline \multirow{3}{*}{ Interdental brush } & \multirow{3}{*}{$\begin{array}{l}2 v s \text { normal } \\
3 v s \text { normal } \\
4 v s \text { normal }\end{array}$} & 8.076 & 0.041 & $1.089-59.883$ & - & - & - & 8.104 & 0.019 & $1.407-46.656$ \\
\hline & & 73.494 & 0.001 & $6.212-869.487$ & 10.873 & 0.028 & $1.302-90.802$ & 21.269 & 0.003 & $2.879-157.137$ \\
\hline & & 208.462 & 0.0001 & $12.453-3489.656$ & 28.776 & 0.010 & $2.249-368.145$ & $12 . .757$ & 0.016 & $1.592-102.229$ \\
\hline \multicolumn{11}{|l|}{ Clinical } \\
\hline \multirow{2}{*}{ Recession } & \multirow{2}{*}{$\begin{array}{l}3 v s 2 \\
4 v s 2\end{array}$} & 8.213 & 0.001 & $2.502-26.959$ & 2.641 & 0.003 & $1.405-4.964$ & 5.630 & 0.0001 & $2.337-13.564$ \\
\hline & & 67.322 & 0.0001 & $11.274-401.996$ & 14.528 & 0.0001 & $4.104-51.431$ & 13.245 & 0.0001 & $4.617-37.992$ \\
\hline \multicolumn{11}{|l|}{ Radiographic } \\
\hline \multirow{3}{*}{ Vertical distance } & \multirow{3}{*}{$\begin{array}{l}2 v s \text { normal } \\
3 v s \text { normal } \\
4 v s \text { normal }\end{array}$} & - & - & - & 2.631 & 0.003 & $1.394-4.965$ & 1.893 & 0.022 & $1.097-3.267$ \\
\hline & & 4.365 & 0.0001 & $2.050-9.295$ & 6.685 & 0.0001 & $3.035-14.725$ & 9.606 & 0.0001 & $3.712-24.858$ \\
\hline & & 14.691 & 0.0001 & $4.973-43.395$ & 15.971 & 0.0001 & $6.029-42.310$ & 17.738 & 0.0001 & $6.298-49.958$ \\
\hline
\end{tabular}

Table 3. Median Values of Clinical and Radiographic Parameters in Relation to Papilla Clinical Appearance [Nordland \& Tarnow Classification (1998)] 14

\begin{tabular}{|c|c|c|c|c|}
\hline \#1.2-1.1 & $\begin{array}{c}\text { Normal } \\
\qquad \begin{array}{c}1 \\
2 \\
3\end{array}\end{array}$ & $\begin{array}{l}1 \\
1 \\
2 \\
1\end{array}$ & $\begin{array}{c}5 \\
5 \\
7 \\
10\end{array}$ & $\begin{array}{l}0 \\
2 \\
4 \\
6\end{array}$ \\
\hline \#1.1-2.1 & $\begin{array}{c}\text { Normal } \\
1 \\
2 \\
3\end{array}$ & $\begin{array}{c}2 \\
2 \\
2.5 \\
2\end{array}$ & $\begin{array}{c}5 \\
7 \\
9 \\
11\end{array}$ & $\begin{array}{l}0 \\
3 \\
4 \\
6\end{array}$ \\
\hline
\end{tabular}


Table 3. cont...

\begin{tabular}{|c|c|c|c|c|}
\hline Papilla & Class & HD $(\mathbf{m m})$ & BC-CP $(\mathbf{m m})$ & Papilla Recession $(\mathbf{m m})$ \\
\hline \multirow{2}{*}{$2.1-2.2$} & Normal & 1 & 5 & 0 \\
& 1 & 1.5 & 6 & 2 \\
& 2 & 1.5 & 8 & 4 \\
& 3 & 1.5 & 10 & 6 \\
\hline
\end{tabular}

$\mathrm{HD}=$ horizontal distance

$\mathrm{BC}-\mathrm{CP}=$ vertical distance

Table 4. Non-Parametric Correlations Between the Radiographic Distances and the Papilla Recession Degree

\begin{tabular}{|c|c|c|c|c|c|c|c|}
\hline & & \multicolumn{2}{|c|}{ Papilla \#1.2-1.1 } & \multicolumn{2}{|c|}{ Papilla \#1.1-2.1 } & \multicolumn{2}{|c|}{ Papilla \#2.1-2.2 } \\
\hline \hline \multirow{3}{*}{ BC-CP } & & HD & BC-CP & HD & BC-CP & HD & BC-CP \\
\hline \multirow{2}{*}{ Papilla recession } & Spearman's rho & 0.181 & $/$ & 0.305 & $/$ & 0.146 & $/$ \\
\cline { 2 - 9 } & p-value & 0.080 & $/$ & $0.002^{*}$ & $/$ & 0.145 & $/$ \\
\cline { 2 - 10 } & Spearman's rho & 0.192 & 0.726 & 0.287 & 0.766 & 0.277 & 0.766 \\
\hline
\end{tabular}

$\mathrm{HD}=$ horizontal distance

$\mathrm{BC}-\mathrm{CP}=$ vertical distance

* Statistically significant

Table 5. Percentage Distribution of the Different Papillae Appearances [Nordland \& Tarnow Classification (1998)] 14 in Relation to the Horizontal Distance (HD)

\begin{tabular}{|c|c|c|c|c|c|c|c|c|}
\hline \multirow[b]{2}{*}{ Papilla } & \multirow[b]{2}{*}{ Class } & \multicolumn{7}{|c|}{ Horizontal Distance (mm) } \\
\hline & & 1 & 1.5 & 2 & 2.5 & 3 & 3.5 & 4 \\
\hline \#1.2-1.1 & $\begin{array}{c}\text { Normal } \\
1 \\
2 \\
3 \\
\text { Total number }\end{array}$ & $\begin{array}{l}31 \\
25 \\
18 \\
26 \\
\mathbf{5 1}\end{array}$ & $\begin{array}{l}31 \\
25 \\
31 \\
13 \\
16\end{array}$ & $\begin{array}{c}8 \\
23 \\
54 \\
15 \\
26\end{array}$ & l & $\begin{array}{c}0 \\
0 \\
100 \\
0 \\
1\end{array}$ & I & I \\
\hline$\# 1.1-2.1$ & $\begin{array}{c}\text { Normal } \\
1 \\
2 \\
3 \\
\text { Total number }\end{array}$ & $\begin{array}{c}18 \\
64 \\
18 \\
0 \\
\mathbf{1 1}\end{array}$ & $\begin{array}{l}41 \\
17 \\
17 \\
25 \\
\mathbf{1 2}\end{array}$ & $\begin{array}{l}27 \\
38 \\
19 \\
16 \\
36\end{array}$ & $\begin{array}{c}15 \\
23 \\
54 \\
8 \\
\mathbf{1 3}\end{array}$ & $\begin{array}{c}6 \\
47 \\
29 \\
18 \\
\mathbf{1 7}\end{array}$ & $\begin{array}{c}0 \\
50 \\
50 \\
0 \\
\mathbf{2}\end{array}$ & $\begin{array}{c}0 \\
60 \\
20 \\
20 \\
\mathbf{5}\end{array}$ \\
\hline \#2.1-2.2 & $\begin{array}{c}\text { Normal } \\
1 \\
2 \\
3 \\
\text { Total number }\end{array}$ & $\begin{array}{l}33 \\
29 \\
21 \\
17 \\
\mathbf{5 2}\end{array}$ & $\begin{array}{l}18 \\
27 \\
27 \\
27 \\
\mathbf{2 2}\end{array}$ & $\begin{array}{c}4 \\
46 \\
29 \\
21 \\
\mathbf{2 4}\end{array}$ & $\begin{array}{c}33 \\
67 \\
0 \\
0 \\
\mathbf{3}\end{array}$ & I & l & I \\
\hline
\end{tabular}

Table 6. Percentage Distribution of the Different Papillae Appearances [Nordland \& Tarnow Classification (1998)] 14 in Relation to the Vertical Distance (BC-CP)

\begin{tabular}{|c|c|c|c|c|c|c|c|c|c|}
\hline \multirow[b]{2}{*}{ Papillae } & \multirow[b]{2}{*}{ Class } & \multicolumn{8}{|c|}{ Vertical Distance (mm) } \\
\hline & & $\leq 4$ & 5 & 6 & 7 & 8 & 9 & 10 & $\geq 11$ \\
\hline \multirow[t]{5}{*}{$\# 1.2-1.1$} & Normal & 38 & 68 & 23 & 0 & 0 & 0 & 0 & 0 \\
\hline & 1 & 62 & 21 & 36 & 17 & 8 & 0 & 0 & 0 \\
\hline & 2 & 0 & 11 & 41 & 83 & 54 & 43 & 40 & 0 \\
\hline & 3 & 0 & 0 & 0 & 0 & 38 & 57 & 60 & 100 \\
\hline & Total number & 13 & 19 & 22 & 6 & 13 & 7 & 5 & 7 \\
\hline
\end{tabular}


Table 6. cont....

\begin{tabular}{|c|c|c|c|c|c|c|c|c|c|}
\hline \multirow{4}{*}{$\# 1.1-2.1$} & & \multicolumn{8}{|c|}{ Vertical Distance (mm) } \\
\hline & 1 & 67 & 29 & 46 & 74 & 58 & 27 & 0 & 0 \\
\hline & 3 & 0 & 0 & 0 & 0 & 0 & 27 & 40 & 67 \\
\hline & Total number & 3 & 17 & 13 & 19 & 12 & 11 & 5 & 12 \\
\hline \multirow{4}{*}{ \#2.1-2.2 } & 1 & 47 & 37 & 61 & 55 & 14 & 0 & 0 & 0 \\
\hline & 2 & 0 & 0 & 22 & 27 & 50 & 80 & 57 & 10 \\
\hline & 3 & 0 & 0 & 0 & 18 & 36 & 20 & 43 & 90 \\
\hline & Total number & 17 & 16 & 1 & 11 & 14 & 5 & 7 & 10 \\
\hline
\end{tabular}

of papilla recession increases too in a statistically significant manner. Furthermore, these data show that age is always positively correlated with the radiographic vertical distance (BC-CP); i.e. an increase in age correlates with a progressive increase in the $\mathrm{BC}-\mathrm{CP}$ vertical distance. This is largely due to physiological consequences of aging: as a matter of fact the BC-CP distance increases with age because of the physiological resorption of the bone crest. Furthermore it is possible that papilla recession increases with age due to a thinning of the mucosa [3]. Thus, as similarly reported by Chang [3,8], age results as being a significant and strong predictor of the degree of papillary recession.

As reported in Table 4 the strength of the relationship between HD and papilla recession is weak. This observation could be explained by the fact that for HD it exists probably a threshold value above which the contact point disappears.

Regarding smoking habit, its influence on the prognosis of papilla was not statistically significant; a possible explanation of this result may be that in our sample the number of heavy smokers ( $\geq 10$ cigarettes/day) is relatively low (17\%).

Taking into consideration the instruments of dental hygiene, in particular interdental brushes, it was observed that the radiographic vertical distance and the papilla recession tended to be greater in patients using these kind of hygienic devices. This association may be explained either as a result of the compressive action of the hygienic instruments or as the need of their use because of peculiar anatomical features; in fact subjects with larger interdental spaces are automatically more inclined to use these instruments for their oral hygiene. Regarding papillary recession instead, the compressive action of such hygiene devices could have promoted the emergence or the exacerbation of the "black holes" $[17,18]$.

Studying the correlations between clinical classes [5] and clinical variables, it results that only the degree of recession affects the class of papilla.

With regard to the biotype variable, despite the presence of a homogenous distribution of the two recognized types in the study sample, no correlation between periodontal biotype and recession of the interdental papillae emerges. This observation suggests that even though the thin biotype may favour the development of recessions of the buccal gingival margin [19], it does not seem to condition the status of the interproximal tissues. In order to confirm this trend new and more focused investigations with a particular accuracy in the periodontal phenotype definition are demanded.

In this work a predominant number of squared teeth subjects was observed. This finding contrasts in some way with what reported by Olsson \& Lindhe [11] where a relevant lower percentage was reported. This discrepancy may be explained by existing differences between both the recording methods and the study samples. In the present study no visual magnification has been used and each measurement has been rounded up to the nearest millimetre. This kind of approximation, could have induced some shifting in tooth shape distribution. Concerning the study samples, an older group of subjects characterize the present study; knowing that an incisal edge wearing is a normal consequence of the ageing process and presupposing that potential racial differences could exist between the two study samples, these arguments could further explain the existing differences.

Previously it has been reported that triangular shaped teeth are subject to a higher risk of papilla recession since they are characterized by a more incisal contact point, compared to square shaped teeth, and consequently are at higher risk of increase in the BC-CP distance [19]. The data from the present study confirm such a predisposition showing how the BC-CP distance and the degree of papillary deficit are significantly greater in subjects with triangular teeth.

Studying the correlations between clinical classes and radiographic variables, it results that the horizontal radiographic distance is independent from papilla class; an opposite result emerges for the vertical radiographic distances that increase as the papilla class increases.

Numerous classification systems of the interdental papillae have been described in the literature $[4,5,20,21]$ and that used in the present work was the one proposed by Nordland and Tarnow in 1998 [14]. This choice was prompted due to its extreme clarity and clinical practicality. Different Authors however have simply divided the papillae into present and absent, depending upon the degree of recession [3, 5, 7], while Chang in 2007 proposed a grouping scheme for 
Table 7. Normal Papilla Percentages [Nordland \& Tarnow Classification (1998) $]_{14}$ and Relative Standard Errors in Relation to the Vertical Distance (BC-CP). Comparison of the Present Data to those Previously Reported by Tarnow et al. (1992) 5 and Cho et al. (2006) $)_{7}$

\begin{tabular}{|c|c|c|c|c|c|c|c|c|c|c|c|c|}
\hline & \multicolumn{12}{|c|}{ Vertical Distance } \\
\hline & $4 \mathrm{~mm}$ & S.E. & $5 \mathrm{~mm}$ & S.E. & $6 \mathrm{~mm}$ & S.E. & $7 \mathrm{~mm}$ & S.E. & $8 \mathrm{~mm}$ & S.E. & $9 \mathrm{~mm}$ & S.E. \\
\hline Tarnow et al. 1992 $_{5}$ & $100^{\S}$ & - & $98^{\S}$ & 1.64 & $56^{\S}$ & 4.69 & $27^{\S}$ & 5.60 & $10^{\S}$ & 6.55 & $25^{\S}$ & 21.65 \\
\hline Cho et al.2006 7 & $89.7^{\S}$ & 5.64 & $58.5^{\S}$ & 6.77 & $35.2^{\S}$ & 6.50 & $7.5^{\S}$ & 4.17 & $5.9^{\S}$ & 5.72 & $0^{\S}$ & - \\
\hline Present study & 100 & - & 94.2 & 3.23 & 71.7 & 6.19 & 63.9 & 8.01 & 25.6 & 6.99 & 13 & 7.02 \\
\hline
\end{tabular}

S.E.: standard error

$\S$ : Data reproduced with permission from the American Academy of Periodontology.

the papillae based upon the dimensions (width and height) of the interdental space [8]. Martegani et al. [4] used a classification pattern previously proposed for the interproximal tissues between dental implants [21]: the measurements were related to the spaces between reference lines running through the highest gingival curvature of the crown-tooth margin and the contact point. While this classification scheme is certainly useful within dental implants, it disregards important points of anatomical reference that are available on natural teeth. All these issues make it difficult to carry out a valid comparison of our results with those obtained by other Authors.

In order to allow a correct comparison with the previous studies of Cho et al. [7] and Tarnow et al. [5] applying a dichotomous classification of the papilla recession (papilla present/papilla absent), we have performed a similar subdivision of our data. Since $63 \%$ of the studied sample used interproximal hygiene devices, that are potentially responsible for a small deficit or flattening of the papillae, we decided to proceed using the grouping system of normal papillae and papillae of class 1, defined in their set as "present papillae", versus class 2 and class 3 papillae grouped together to form the "absent papillae" set. Comparing the so obtained data to those of the two previous studies, as reported on (Table 7), it is possible to observe a quite similar distribution trend in relation to the vertical distance. In spite of this, it is interesting to observe that from our evaluation only after $7 \mathrm{~mm}$ becomes predominant the percentage of "absent papillae". Since the other studies didn't make any distinguishing between anterior and posterior papillae it could be speculated that central and lateral upper papillae manifest higher tolerance about this parameter. Analyzing the data of (Table 6) becomes quite evident that central papilla has a focal role on this specific observation.

Regarding the data that refer to the distribution of the lateral and central papillae in relation to the radiographic horizontal distance, the tendency does not follow the same trend reported by the study of Cho et al. in 2006 [7]. The Authors stated that the interdental papillae were present in $77.8 \%$ of cases when the radiographic horizontal distance was $1 \mathrm{~mm}$, decreasing to $53.7 \%$ with a distance of $2 \mathrm{~mm}$, and progressively decreasing even further as the horizontal distance increases. In the present study it is shown that the "present papillae" are quite uniformly distributed and do not depend upon the horizontal radiographic distance. However, these different results should take into account the fact that the Authors calculated the horizontal distance level with a more coronal point than the interproximal bone, while we specify this distance as being on the same level of the CEJ. Another relevant difference with our study is that the Authors studied both anterior and posterior papillae.

In the study of Martegani et al. [4], the Authors assessed the interdental papillae of the antero-superior sextant (from \#12 to \#22) confirming that an increase of HD distance correlates with an increase in the degree of interdental papillary recession. Nevertheless this evidence is not supported by clear numerical data, unless a cut-off value equal to $2.4 \mathrm{~mm}$ for the HD distance, above which the radiographic vertical distance stops to act as predictive factor for the presence of papillae. Concerning this critical value, from our data it results that such distances were either reached or exceeded in only 24 interproximal central areas $(25 \%)$ and in as little as only 4 cases $(2 \%)$ within the interdental lateral areas (Table 5). This brings us to suppose that the critical horizontal distance of $2.4 \mathrm{~mm}$ is not probably representative of the dental norm for Caucasian subjects, as is the case in our paper.

Another study published in 2008 [3] focused on this topic analysing the upper central papilla. The Author reported that the mean horizontal distances for the groups with and without papillary recession $(1.96 \pm 0.50$ and $1.67 \pm 0.42 \mathrm{~mm}$ respectively) were significantly different. It was also described a cut-off value of $2.05 \mathrm{~mm}$ for the presence of papillae and it was found that with each $1 \mathrm{~mm}$ distance increase, the probability of central papillary recession increased too. In our study, only comparing data concerning the central papilla, such trend is not observable. Our less numerous sample (96 versus 310) combined with the low presence of central papillae with horizontal distances greater than $2 \mathrm{~mm}(38 \%)$ might justify this difference between the results.

From the overall comparison of the data presented in the literature we can hypothesize that in the presence of a horizontal distance not clearly defined, but at least superior to 2 $\mathrm{mm}$, there is a lower chance to have normal class papillae.

The positive correlation detected between the $\mathrm{BC}-\mathrm{CP}$ increase and the higher risk of papillae recession is in accordance with what reported by Chang in 2008 [3]; in this study of a single anterior site, the mean $\mathrm{BC}-\mathrm{CP}$ distances in the groups with and without papillary recession $(6.19 \pm 0.91$ and $5.24 \pm 0.95 \mathrm{~mm}$, respectively) were significantly different. Furthermore, the Author reported the cut-off point for the 
BC-CP distance to be $5.41 \mathrm{~mm}$, and each $1 \mathrm{~mm}$ increase in distance increased the probability of central papillary recession by 3.04-fold. Comparing these data to the results of the present study regarding the central papilla, a very similar cut-off point can be seen.

All studies on this subject confirm the importance of the $\mathrm{BC}-\mathrm{CP}$ distance that determines presence or absence of papillae, sharing the observation that at distances greater than 5 $\mathrm{mm}$ there are net decreases in the presence of papillae.

By comparing the central papilla and the two lateral papillae it emerges that clinical and radiographic differences exist.

If a BC-CP cut-off distance of $5 \mathrm{~mm}$ existed for all the papillae, a progressive dimensional recession would be observed; however, the recession of the central papilla manifests more gradually than that of the lateral papillae, maintaining a clinical presence, more aesthetically acceptable, until a vertical radiographic distance of $8 \mathrm{~mm}$.

Furthermore, the horizontal and vertical distances of the central papilla in class 1,2 and 3 are greater for a distance up to $1 \mathrm{~mm}$ for the $\mathrm{HD}$ and up to $2 \mathrm{~mm}$ for the $\mathrm{BC}-\mathrm{CP}$ than those of the corresponding lateral papillae. For the central papilla, the correlation between the horizontal radiographic distance and the recession is always different than that of the lateral papillae.

The observed differences could be explained by distinct anatomical characteristics of the areas. In fact, in the region between the central incisors two particular anatomical structures exist forming tight associations with the interdental tissues: the naso-palatine canal and the insertions of the vestibular fraenulum. Regarding the surrounding bone, papillae have other anatomical differences: the symphysis bone, including its cartilage component, and the interadicular septum, wider between the central incisors. These anatomical features could be responsible for structural, nutritional and trophic influences that are specific to the central over the lateral papillae, and may offer different reactions to the traumatic or infective insults.

\section{CONCLUSIONS}

Knowledge about the factors that influence the papillary structure provides an essential support for periodontal, orthodontic and prosthetic treatments; it makes way for improved planning of the dental interventions aimed at the preservation or at the restoration of a pleasing aesthetic result.

The results of this study highlight the importance of age, tooth crown ratio (width/height) and radiographic vertical distance as factors that determine the morphology of the anterior papillae. Furthermore this study shows that anatomical differences exist between central and lateral papillae.

The clinician involved in a treatment planning of the second sextant, can find in these findings a guide and exhortation to respect the physiological differences that exist between interdental papillae. Following these clinical indications it is possible to preserve or restore a periodontal natural appearance of the area with harmonious, stable and satisfactory results.

Finally, the results of this study suggest to not disregard the specifics of distinct anatomical areas during future analysis upon this subject.

\section{ACKNOWLEDGEMENTS}

The Authors are grateful to Dr Maria Rosaria Gatto, Department of Dental Sciences "Alma Mater Studiorum" University of Bologna, for her contribution to statistical analysis.

\section{CONFLICT OF INTEREST}

No external funding, apart from the support of the Authors' institution, was available for this study. There was no conflict of interest.

\section{REFERENCES}

[1] Glossary of Periodontal Terms. $4^{\text {th }}$ ed. Chicago, Illinois, USA. The American Academy of Periodontology. 2001: p. 22.

[2] Zetu L, Wang HL. Management of inter-dental/inter-implant papilla. J Clin Periodontol 2005; 32: 831-9.

[3] Chang LC. Assessment of parameters affecting the presence of the central papilla using a non-invasive radiographic method. J Periodontol 2008; 79: 603-9.

[4] Martegani P, Silvestri M, Mascarello F, et al. Morphometric study of the interproximal unit in the esthetic region to correlate anatomic variables affecting the aspect of soft tissue embrasure space. J Periodontol 2007; 78: 2260-5.

[5] Tarnow DP, Magner A, Fletcher P. The effect of the distance from the contact point to the crest of bone on the presence or absence of the interproximal dental papilla. J Periodontol 1992; 63: 995-6.

[6] Pini PG, Rotundo R, Cortellini PP, Tinti C, Azzi R. Interdental papilla management: a review and classification of the therapeutic approaches. Int J Periodontics Restorative Dent 2004; 24: 246-55.

[7] Cho HS, Jang HS, Kim DK, et al. The effects of interproximal distance between roots on the existence of interdental papillae according to the distance from the contact point to the alveolar crest. J Periodontol 2006; 77: 1651-7.

[8] Chang LC. The association between embrasure morphology and central papilla recession. J Clin Periodontol 2007; 34: 432-6.

[9] Loe H, Silness J. The gingival index, the plaque index and the retention index systems. J Periodontol 1967; 38: 610-16.

[10] Dietrich T, Bernimoulin JP, Glynn RJ. The effect of cigarette smoking on gingival bleeding. J Periodontol 2004; 75: 16-22.

[11] Olsson M, Lindhe J. Periodontal characteristics in individuals with varying form of the upper central incisors. J Clin Periodontol 1991; 18: 78-82.

[12] Jia-Hui Fu, Yeh CY, Chan HL, Tatarakis N, Leong DJ, Wang HL. Tissue biotype and its relation to the underlying bone morphology. J Periodontol 2010; 81: 569-74.

[13] Kan JY, Rungcharassaeng K, Umezu K, Kois JC. Dimensions of peri-implant mucosa: an evaluation of maxillary anterior single implants in humans. J Periodontol 2003; 74: 557-62.

[14] Nordland WP, Tarnow DP. A classification system for loss of papillary height. J Periodontol 1998; 69: 1124-6.

[15] Krithika AC, Kandaswamy D, Velmurugan N, Krishna VG. Nonmetallic grid for radiographic measurements. Aust Endod J 2008; 34(1): 36-8.

[16] Landis RJ, Kock GG. The measurement of observer agreement for categorical data. Biometrics 1977; 33: 159-74.

[17] Cantor MT, Stahl SS. The effect of a water pressure cleansing device on the human interdental col, a histologic study. J Periodontol 1968; 39: 43.

[18] Checchi L, Biagini G, Zucchini C, De Luca M. Interdental therapy by brushing. clinical and morphological considerations. Quintessence Int 1991; 22: 483-9.

[19] Kois JC. Predictable single tooth peri-implant esthetics: five diagnostic keys. Compend Contin Educ Dent 2001; 22: 199-206. 
[20] Cardaropoli D, Re S, Corrente G. The papilla presence index (PPI): a new system to assess interproximal papillary levels. Int J Periodontics Restorative Dent 2004; 24: 488-92.
[21] Jemt T. Regeneration of gingival papillae after single-implant treatment. Int J Periodontics Restorative Dent 1997; 17: 326-33.

(C) Montevecchi et al.; Licensee Bentham Open.

This is an open access article licensed under the terms of the Creative Commons Attribution Non-Commercial License (http://creativecommons.org/licenses/by-nc/3.0/) which permits unrestricted, non-commercial use, distribution and reproduction in any medium, provided the work is properly cited. 